\title{
Computer Navigation for Revision Total Hip Arthroplasty Reduces Dislocation Rates
}

\author{
Zlatan Cizmic MD ${ }^{1}$, Kaitlin Carroll $\mathrm{MS}^{2}$, Seth Jerabek $\mathrm{MD}^{2}$, Wayne \\ Paprosky $\mathrm{MD}^{3}$, Peter Sculco MD², Alejandro Gonzalez Della Valle $\mathrm{MD}^{2}$, \\ Patrick Meere $\mathrm{MD}^{4}$, Alexander McLawhorn, $\mathrm{MD}^{2}$, Ran Schwarzkopf $\mathrm{MD}^{4}$, \\ Friedrich Boettner $\mathrm{MD}^{2}$, David Mayman $\mathrm{MD}^{2}$, and Jonathan Vigdorchik \\ $\mathrm{MD}^{2 *}$ \\ ${ }^{1}$ Ascension Providence Hospital \\ ${ }^{2}$ Hospital for Special Surgery \\ ${ }^{3}$ Central DuPage Hospital \\ ${ }^{4} \mathrm{NYU}$ Langone Health \\ zlatancizmic91@gmail.com, carrollk@hss.edu, jerabeks@hss.edu, \\ parp1210@gmail.com, sculcop@hss.edu, gonzaleza@hss.edu, \\ patrick.meere@nyulangone.org, mclawhorna@hss.edu, \\ ran.schwarzkopf@nyulangone.org, boettnerf@hss.edu, maymand@hss.edu, \\ and vigdorchikjehss.edu
}

\begin{abstract}
INTRODUCTION: Computer-assisted hip navigation offers more accurate placement of hip components, potentially avoiding impingement, edge-loading, and dislocation; major causes of failure leading to revision THA. As such, the use of computer navigation may be particularly beneficial in the revision THA population. The purpose of this study was to determine if the use of computer-assisted hip navigation reduced the rate of dislocation in patients undergoing revision THA.
\end{abstract}

METHODS: A retrospective review of 72 patients undergoing computer-navigated revision THA between February 2016 and May 2017 was performed. Demographics, indications for revision, type of procedure performed, and postoperative complications were collected for all patients. Clinical follow-up was recorded at 3-months, 1-year and 2-years.

RESULTS: All 72 patients (48\% female; $52 \%$ male) were included in the final analysis. Mean age of patients was $70.4 \pm 11.2$ years. Mean BMI was $26.4 \pm 5.2 \mathrm{~kg} / \mathrm{m} 2$. The most 
Computer Navigation for Revision Total Hip Arthroplasty Reduces Dislocation Rates Z. Cizmic et al.

common indications for revision THA were instability (31\%), aseptic loosening (29\%), osteolysis/eccentric wear (18\%), infection (11\%), and miscellaneous (11\%). At 3months, 1-year, and 2-years there were no dislocations in any patients (0\%). Compared to preoperative dislocation values, there was a significant reduction in the rate of dislocation with the use of computer-assisted hip navigation ( $31 \%$ vs. $0 \%$; $<<0.05)$.

DISCUSSION: Our study demonstrates a significant reduction in the rate of dislocation following revision THA with the use of computer navigation. Although the cause of postoperative dislocation is often multifactorial, the use of computer-assisted surgery may help to curtail femoral and acetabular malalignment in revision THA.

\section{Introduction}

Despite an overall high success rate, up to $12 \%$ of total hip arthroplasties (THA) require revision surgery ${ }^{1}$, of which over 1 in 5 are second revisions ${ }^{2}$. The major precipitating factors for revision surgery are instability and dislocation of the implanted components, the risks of which are higher following rTHA than after primary THA ${ }^{3}$. By some estimates, as many as $33 \%$ of rTHA procedures ultimately require a re-revision ${ }^{4}$, and up to $35 \%$ of these failed revisions are a consequence of instability ${ }^{3}$. Dislocation similarly contributes to rTHA, as the rate of dislocation following rTHA is up to 6 times higher than following primary $\mathrm{THA}^{5,6}$. Impingement, edge-loading and component wear also influence failures following TTHA $^{7,8}$, underscoring the multifactorial nature of dislocation following THA.

Computer-assisted navigation offers the potential for improved accuracy when placing hip components during THA and may represent a viable method for improving long-term post-operative stability, a key in limiting dislocation and instability. In primary THA, navigation has demonstrated an ability to improve the accuracy with which components are placed, resulting in fewer acetabular cup components placed outside of Lewinnek's safe zone ${ }^{9}$ and decreasing the rates of dislocation and leg length differentials greater than $5 \mathrm{~mm}^{10-13}$. Despite this success in primary THA, however, there is little evidence available regarding the role of navigation in rTHA.

The purpose of this study was to determine if the use of computer-assisted hip navigation reduced the rate of dislocation in patients undergoing rTHA. Our hypothesis was that the use of navigation would effectively lower the rate of dislocation following rTHA.

\section{Methods}

This study was a multicenter, retrospective review of patients undergoing computer navigationassisted revision THA. Institutional review board (IRB) approval was obtained by all participating institutions prior to data collection.

Patients undergoing navigation-assisted revision total hip arthroplasty between February 2016 and May 2017 were considered eligible for inclusion. All procedures were performed with the assistance of an imageless navigation device (Intellijoint $\mathrm{HIP}^{\circledR}$, Intellijoint Surgical, Inc., Waterloo, ON) ${ }^{14}$. Patients were excluded from the study if intraoperative removal of the navigation device prior to recording of final measurements was performed, properly scaled pre- and post-operative anteriorposterior (AP) radiographs were not available, or if radiographic measurement landmarks on radiographs were not able to be properly reproduced or identified.

Patients were evaluated prior to surgery per the institutions' standard of care and followed-up postoperatively at 3-months, 1-year, and 2-years. Demographic data and data regarding the indication for revision, type of procedure performed, and post-operative complications were collected for all patients. 
Computer Navigation for Revision Total Hip Arthroplasty Reduces Dislocation Rates Z. Cizmic et al.

Dislocations, hospital readmissions and revision surgeries were collected at all follow-up visits. Dislocations were defined as any episode that required closed or open reduction, or revision arthroplasty.

Final component position was measured prospectively using the navigation device and stored on the workstation.

Data is presented as percentages and was analyzed using appropriate comparative statistical tests (ztests and independent samples t-tests). Mean values are presented as mean (standard deviation) or mean (range). Alpha was set a priori at 0.05 for all statistical comparisons.

\section{Results}

77 patients undergoing rTHA using computer navigation were reviewed. 72 of the 77 patients were eligible for inclusion in this study. Of the five excluded from the study, three did not have preoperative AP pelvis radiographs, one was a conversion from a dynamic hip screw, and one had an acetabular construct instead of an acetabular cup. Demographic data is summarized in Table I. The most common indications for revision THA were instability (31\%), aseptic loosening (29\%), osteolysis/eccentric wear $(18 \%)$, infection $(11 \%)$, and miscellaneous $(11 \%)$. During revision procedures, polyethylene component was most commonly changed (46\%), followed by femoral head (39\%), and acetabular component (15\%).

\begin{tabular}{|c|c|}
\hline Table 1: Demographic Summar & \\
\hline Variable & Result, n/N (\%) \\
\hline \multicolumn{2}{|l|}{ Gender } \\
\hline Male & $37 / 72(52 \%)$ \\
\hline Female & $35 / 72(48 \%)$ \\
\hline Body mass index (BMI) & $26.4 \pm 5.2$ \\
\hline \multicolumn{2}{|l|}{ Indications for revision } \\
\hline Instability & $22 / 72(31 \%)$ \\
\hline Aseptic loosening & $21 / 71(29 \%)$ \\
\hline Osteolysis/eccentric wear & $13 / 72(18 \%)$ \\
\hline Infection & $8 / 72(11 \%)$ \\
\hline Miscellaneous & $8 / 72(11 \%)$ \\
\hline \multicolumn{2}{|l|}{ Components changed } \\
\hline Polyethylene & $33 / 72(46 \%)$ \\
\hline Femoral head & $28 / 72(39 \%)$ \\
\hline Acetabular component & $11 / 72(15 \%)$ \\
\hline Dislocations & $0 / 72(0 \%)$ \\
\hline
\end{tabular}

At 3-months, 1-year and 2-years follow-up, there were no dislocations among any study patients $(0 \%)$. Compared to preoperative dislocation values, there was a significant reduction in the rate of dislocation with the use of computer-assisted hip navigation ( $31 \%$ vs. $0 \%$; $p<0.05$ ).

\section{Discussion}

Dislocation following revision THA ultimately necessitates a second revision, a costly procedure with increased risks of morbidity. Computer-assisted navigation offers the potential for improved accuracy in the placement of hip components - an important factor in avoiding dislocation, 
impingement and edge-loading. Navigation systems have demonstrated advantages in primary THA but have not been the subject of studies of revision THA. We evaluated the 3-month, 1-year and 2-year follow-up data from 72 patients undergoing revision THA with a novel navigation device and noted a significant decrease in the rate of dislocation.

We observed no dislocations during the 2-year follow-up period of this study. In a retrospective review of 40 patients, Chang et al. ${ }^{15}$ observed no dislocations over an average of 80.7 months of followup. Prior to revision surgery, 23 of 40 cups were outside of the safe zone, however, there were no outliers after rTHA. These findings are similar to our study where no outliers were noted following rTHA. Likewise, Yun et al. ${ }^{16}$ evaluated post-operative findings in 28 patients undergoing primary or revision THA using navigation. The authors reported that of the 12 revision surgeries performed, there were no dislocations noted at 17 months of follow-up. These authors also noted a lack of outliers to the safe zone following revision. Prior to revision, $70 \%$ of cups were outside of the safe zone; however, following revision surgery, all revised cups were within Lewinnek's safe zone.

Our study is not without limitations. The retrospective nature of the study and the lack of a nonnavigated control group may limit the strength of the conclusions. However, the long-term follow-up and multicenter design may offset these concerns. We were able to gather data in both the short-term and long-term, thus addressing concerns raised by hospitals and payers (90-day follow-up), and patients (long-term follow-up).

Our study demonstrates a significant reduction in the rate of dislocation following revision THA with the use of computer navigation. Although the cause of postoperative dislocation is often multifactorial, the use of computer-assisted surgery may help to curtail femoral and acetabular malalignment in revision THA.

\section{References}

1. Bozic KJ, Kurtz SM, Lau E, Ong K, Vail TP, Berry DJ. The Epidemiology of Revision Total Hip Arthroplasty in the United States. J Bone Jt Surgery-American Vol [Internet] 2009 [cited 18 Apr 2018];91(1):128-133.

2. Garellick G, Karrholm J, Lindahl H, Malchau H, Rogmark C RO. Swedish Hip Arthroplasty Register Annual Report. 2013;

3. Plate JF, Brown ML, Wohler AD, Seyler TM, Lang JE. Patient Factors and Cost Associated with 90-Day Readmission Following Total Hip Arthroplasty. J Arthroplasty [Internet] 2016 [cited 19 Sep 2018];31(1):49-52.

4. Bischel O, Seeger JB, Seeger J, Krüger M, Krüge M, Bitsch RG, et al. Multiple Acetabular Revisions in THA - Poor Outcome Despite Maximum Effort. Open Orthop J [Internet] 2012 [cited 19 Sep 2018];6(1):488-94.

5. Schairer WW, Sing DC, Vail TP, Bozic KJ. Causes and Frequency of Unplanned Hospital Readmission After Total Hip Arthroplasty. Clin Orthop Relat Res [Internet] 2014 [cited 19 Sep 2018];472(2):464-470.

6. Ong KL, Lau E, Suggs J, Kurtz SM, Manley MT. Risk of Subsequent Revision after Primary and Revision Total Joint Arthroplasty. Clin Orthop Relat Res [Internet] 2010 [cited 19 Sep 2018];468(11):3070-3076.

7. Davenport D, Kavarthapu V. Computer navigation of the acetabular component in total hip arthroplasty: a narrative review. EFORT open Rev [Internet] 2016 [cited 19 Sep 2018];1(7):279285.

8. Nevelos J, Johnson A, Heffernan C, Macintyre J, Markel DC, Mont MA. What factors affect posterior dislocation distance in THA? Clin Orthop Relat Res [Internet] 2013 [cited 19 Sep 2018];471(2):519-26. 
Computer Navigation for Revision Total Hip Arthroplasty Reduces Dislocation Rates Z. Cizmic et al.

9. Lewinnek GE, Lewis JL, Tarr R, Compere CL, Zimmerman JR. Dislocations after total hipreplacement arthroplasties. J Bone Joint Surg Am [Internet] 1978 [cited 8 Jun 2018];60(2):217-20.

10. Lass R, Kubista B, Olischar B, Frantal S, Windhager R, Giurea A. Total Hip Arthroplasty Using Imageless Computer-Assisted Hip Navigation. J Arthroplasty [Internet] 2014 [cited 19 Sep 2018];29(4):786-791.

11. Gurgel HMC, Croci AT, Cabrita HABA, Vicente JRN, Leonhardt MC, Rodrigues JC. Acetabular Component Positioning in Total Hip Arthroplasty With and Without a Computer-Assisted System: A Prospective, Randomized and Controlled Study. J Arthroplasty [Internet] 2014 [cited 19 Sep 2018];29(1):167-171.

12. Upadhyay A, York S, Macaulay W, McGrory B, Robbennolt J, Bal BS. Medical Malpractice in Hip and Knee Arthroplasty. J Arthroplasty [Internet] 2007 [cited 19 Sep 2018];22(6):2-7.e4.

13. Ranawat CS. The pants too short, the leg too long! Orthopedics [Internet] 1999 [cited 19 Sep 2018];22(9):845-6.

14. Paprosky WG, Muir JM. Intellijoint HIPß: a 3D mini-optical navigation tool for improving intraoperative accuracy during total hip arthroplasty. Med Devices (Auckl) [Internet] 2016 [cited 19 Sep 2018];9:401-408.

15. Chang J-D, Kim I-S, Prabhakar S, Mansukhani SA, Lee S-S, Yoo J-H. Revision Total Hip Arthroplasty Using Imageless Navigation With the Concept of Combined Anteversion. $J$ Arthroplasty [Internet] 2017 [cited 19 Sep 2018];32(5):1576-1580.

16. Yun HH, Yoon J-R, Yu JJ, Seo H-S. Navigated Acetabular Cup Fixation for Acetabular Deformity or Revision Total Hip Arthroplasty. Hip Pelvis [Internet] 2014 [cited 19 Sep 2018];26(3):150. 